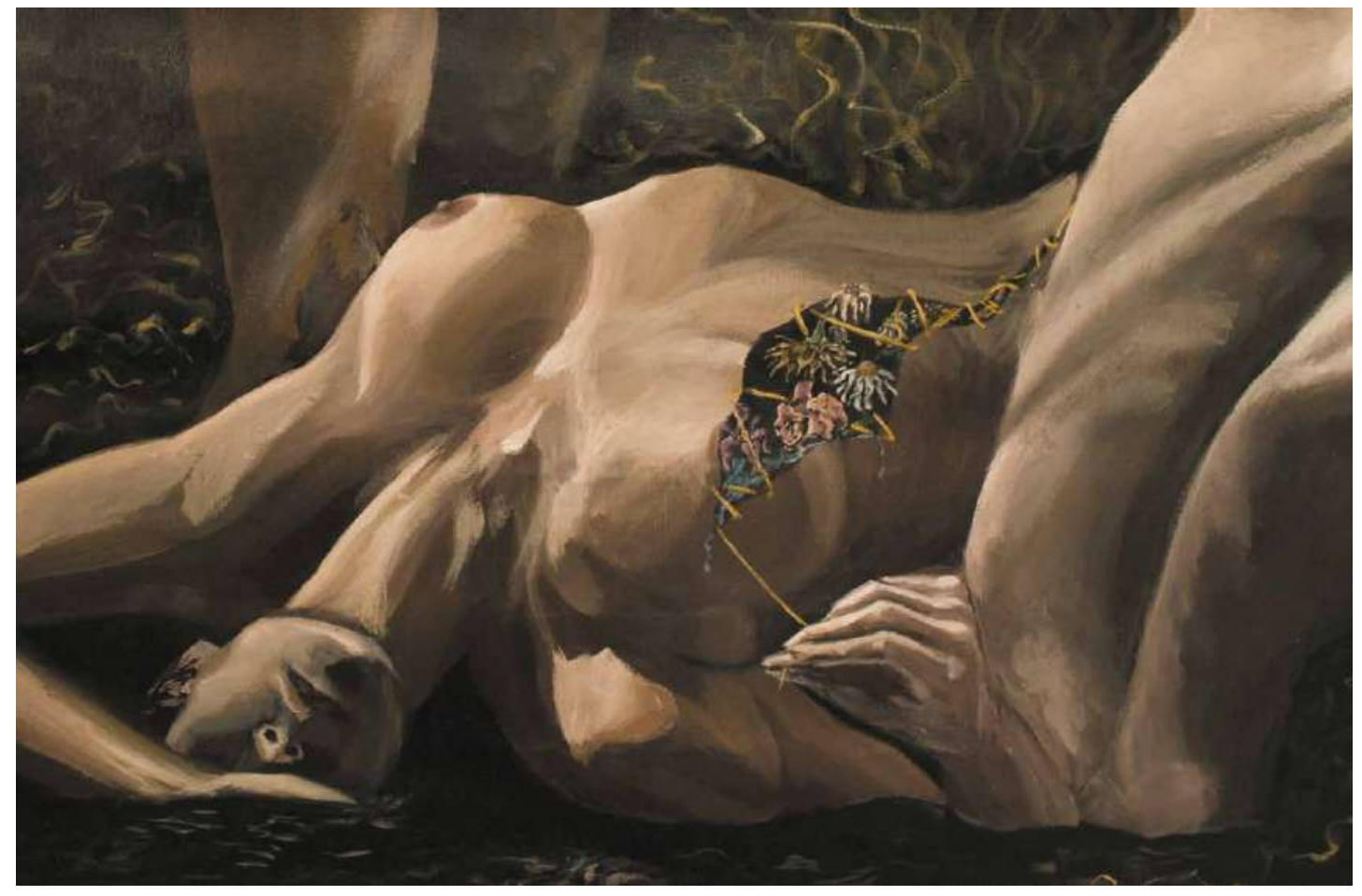

Artista invitada

Sara Ramírez Rodas

La muerte, la consciencia pura (detalle)

Pintura acrílica sobre lona

2019

Cortesía Revista Ojo de Pez 


\title{
Violaciones graves a derechos humanos de comunidades LGBTI en el conflicto armado interno colombiano como crimen de lesa humanidad*
}

\author{
Gloria Cristina Martínez Martínez (Colombia)** \\ Robinson Sánchez Tamayo (Colombia)*** \\ Adelaida María Ibarra Padilla (Colombia) ${ }^{* * * *}$
}

\section{Resumen}

Las personas LGBTI son víctimas de diferentes tipos de violencia que pueden constituir delitos ordinarios, crímenes de prejuicio y crímenes de lesa humanidad. El propósito de este artículo es analizar las debilidades y fortalezas del marco normativo de investigación y juzgamiento de las violencias contra este tipo de población cometidas en el conflicto armado interno en Colombia, según las anteriores categorías. Se recurre al método dogmático jurídico con revisión doctrinal y análisis documental. El estudio concluye que formas de violencia contra personas LGBTI como asesinato, violencia sexual, tortura, desplazamiento y desaparición forzada en el conflicto armado deben investigarse y sancionarse como crímenes de lesa humanidad, a pesar de que tal tipificación no esté contemplada en el derecho penal doméstico.

\footnotetext{
* Producto derivado del Proyecto de investigación Violaciones graves de derechos humanos de comunidades LGBTI en el contexto del conflicto armado como crimen de lesa humanidad, código INVDER 2565, financiado por la Vicerrectoría de Investigaciones, Universidad Militar Nueva Granada, vigencia 2019.

** Abogada. Magíster en Ciencias Penales y Criminológicas. Profesora e investigadora de la Universidad Militar Nueva Granada, co-líder de la Red de Estudios Sociojurídicos Comparados y Políticas Públicas de la misma entidad, en la línea de investigación Política Criminal, Derecho Penal y Criminología. Correo electrónico: gloria.martinezm@unimilitar.edu.co - Orcid: 0000-0001-5759-9147 - Google Scholar: https://scholar.google.com/citations?user=T5HTBLIAAAAJ\&hl=es

*** Abogado. Magíster en Derecho. Candidato a Doctor en Derecho de la Universidad de los Andes. Docente e investigador de la Facultad de Derecho, Universidad Militar Nueva Granada. Correo electrónico: robinson.sanchez@unimilitar.edu.co - Orcid: 0000-0003-2343-3637 - Google Scholar: https://scholar.google.com/citations?hl=es\&user=H1vmPwcAAAAJ

**** Abogada. Magíster en Derecho Internacional. Doctora en Derecho. Profesora e investigadora de la Facultad de Derecho, Universidad Militar Nueva Granada. Correo electrónico: adelaida.ibarra@, unimilitar.edu.co - Orcid: 0000-0002-4921-1664 - Google Scholar: https://scholar.google.com/citation $s ? h l=e s \& u s e r=r W P t B x Y A A A A J$
} 


\title{
Palabras clave
}

Conflicto Armado; Derechos Humanos; Derecho Internacional Humanitario; Crímenes de Lesa Humanidad; LGBTI; Colombia.

Fecha de recepción: julio de 2020

- Fecha de aprobación: noviembre de 2020

\section{Cómo citar este artículo}

Martínez Martínez, Gloria Cristina; Sánchez Tamayo, Robinson y Ibarra Padilla, Adelaida María. (2021). Violaciones graves a derechos humanos de comunidades LGBTI en el conflicto armado interno colombiano como crimen de lesa humanidad. Estudios Políticos (Universidad de Antioquia), 60, pp. 179-202. DOI: 10.17533/udea.espo.n60a08

\section{Serious Violations of Human Rights of LGBTI Communities in the Colombian Internal Armed Conflict as a Crime Against Humanity}

\begin{abstract}
[180] LGBTI people are victims of different types of violence, which can constitute ordinary crimes, crimes of prejudice, and crimes against humanity. The purpose of this article is to analyze the weaknesses and strengths of the regulatory framework for investigation and prosecution of violence against LGBTI people committed in the armed conflict in Colombia, according to the previous categories. It uses the dogmatic legal method with doctrinal review and documentary analysis. The study concludes that forms of violence against LGBTI persons such as murder, sexual violence, torture, displacement, and forced disappearance in the scenary of the armed conflict should be investigated and punished as crimes against humanity, even though such crime is not contemplated in domestic criminal law.
\end{abstract}

\section{Keywords}

Armed Conflict; Human Rights; International Human Rights; Crimes Against Humanity; LGBTI; Colombia. 
Violaciones graves a derechos humanos de comunidades LGBTI en el conflicto armado...

\section{Introducción}

La investigación, juzgamiento y sanción de las violencias contra personas lesbianas, gais, bisexuales, transgénero e intersexuales (LGBTI) debe distinguir, por un lado, los atentados en los cuales existe un propósito del autor fundado en el prejuicio hacia las expresiones de género, identidad de género y orientación sexual, de aquellas conductas en las cuales esos móviles no están presentes; por el otro, debe identificar si los comportamientos criminales se realizan de manera sistemática y generalizada, como parte de un plan o política de Estado.

Cuando las violencias contra personas LGBTI tienen un trasfondo de discriminación y, además, cumplen un patrón de continuidad que perdura en el tiempo, en las cuales han participado agentes del Estado, procede su investigación y juzgamiento como crímenes de lesa humanidad, a pesar de que, en el ordenamiento jurídico interno, aún no se haya tipificado esta categoría delictiva.

El propósito de este artículo es analizar las debilidades y fortalezas del marco normativo de investigación y juzgamiento de las violencias cometidas contras las personas LGBTI en el conflicto armado interno colombiano. Se emplea un estudio dogmático-jurídico, con alcance descriptivo y enfoque cualitativo. Se recurre a fuentes documentales tales como doctrina, literatura científica especializada e informes oficiales y de organizaciones no gubernamentales sobre la materia.

En este artículo se realiza la diferenciación conceptual entre género, identidad de género, expresión de género y orientación sexual; caracteriza las violencias contra personas LGBTI como instrumentos de control territorial, sistemáticos y generalizados, desligándolas de los crímenes por prejuicio y de los delitos ordinarios; analiza las fortalezas del sistema normativo colombiano que, en la incorporación paulatina del derecho internacional, ha transitado de la aplicación del aforismo nullum crimen, nulla poena sine lege al postulado nullum crimen sine iure para posibilitar el juzgamiento por tribunales nacionales de crímenes internacionales; y examina las debilidades del ordenamiento jurídico interno, esto es, la resistencia de ampliar el principio de legalidad para condenar los crímenes internacionales, los precarios registros de denuncias sobre violaciones a los derechos de las personas LGBTI, la existencia de prejuicios en el poder investigativo y judicial que, ausentes de un enfoque 
de género, desconocen la existencia de móviles específicos y contextos particulares de dominio como determinantes de la adecuación típica.

Con esto presente, existen móviles que llevan a perpetrar violencias a las personas LGBTI, en razón a su identidad, expresión de género y orientación sexual, en contextos de dominación, que no están presentes en violencias contra heterosexuales. La reconstrucción probatoria de los anteriores elementos visibiliza la gravedad de una conducta que, al ser sistemática y generalizada, constituye crimen de lesa humanidad.

\section{Género, identidad de género, expresión de género y orientación sexual}

A partir de la década de 1960 los estudios de género han reflexionado sobre la distribución de poder que se desprende de la asignación de roles sociales de las personas según se identifiquen como hombres o mujeres (Scott, 1986; Burin, 1996; Cranny-Francis, Waring, Stavropoulos y Kirkby, 2017). El género se concibe como una construcción social (Haraway, 1995; Butler, 2007; Lamas, 2013), lo que se entiende como femenino y masculino ${ }^{1}$ se refiere a características conductuales, culturales y psicológicas de las personas

[182] que se asumen socialmente como hombres o mujeres (Morrow y Messinger, 2006). Por lo tanto, se opone a consideraciones biologicistas centradas en las características biológicas, anatómicas, hormonales, morfológicas y fisiológicas: «lo que la distinción busca poner en evidencia es que una cosa son las diferencias biológicamente dadas (sexo) y otra la significación que culturalmente se les asigna a esas diferencias (género)» (Jaramillo, 2020, p. 29). Asimismo, «el sexo clasifica a las personas como machos, hembras e intersexuales con base a las características genotípicas y fenotípicas del cuerpo; mientras el género [estudia] las representaciones sociales que se construyen sobre el sexo y los roles que en virtud de éste son atribuidos a las personas» (Sánchez, 2013, p. 7).

El sistema sexo-género se formó como un conjunto de disposiciones socioculturales —normas - que transforman la sexualidad biológica en prácticas humanas y las relaciones sociales que de ellas se derivan (Rubin, 1986). Este par teórico se ha erigido en relaciones hegemónicas de poder (Millet, 1995) y opresión (Firestone, 1976) de heterosexualidad obligatoria

\footnotetext{
${ }^{1}$ Existen personas que no se sienten conformes con estas categorías o fluyen entre ellas, reconociéndose como personas con género no conforme, con género fluido o no binarias.
} 
Violaciones graves a derechos humanos de comunidades LGBTI en el conflicto armado...

como indicador de adscripción o normalización social (Aguilar, 2008) utilizado para diferenciar, manipular (Butler, 2007) y ejercer violencia contra personas que transgreden la asignación del género al sexo.

La idea naturalizada del sexo esconde los dispositivos discursivos y de poder que definen la idea «natural» del sexo y, por ende, del género, bajo esa lógica de la relación causal del binarismo sexo-género y naturaleza-cultura (Butler, 2007). La autora critica que bajo ese binarismo se pretende mostrar una idea «natural» del sexo que es precultural y prenormativo — previo a la norma patriarcal - como un estado previo al concepto del género que aparece como contingente y definido cultural y normativamente - dentro de la norma patriarcal-, lo cual sustenta y reafirma la dicotomía de la diferencia sexual. Así, Judith Butler utiliza el texto de Gayle Rubin (1986) para explicar cómo el sexo —el antes- es definido en términos normativos, es decir, convertido en género - el después—, para determinar unas prácticas sexuales subalternas. Considera que ese «antes» solo puede ser determinado en el marco ofrecido por el «después», por lo que cuestiona la preexistencia de esa categoría natural del sexo que no puede ser leída sin los marcos discursivos y normativos establecidos por el género.

Una parte de la literatura ha venido recogiendo las reflexiones de Rubin sobre el sistema sexo-género para explicar cómo de la categoría sexo se pueden derivar dos acepciones: a) el reconocimiento biológico de los cuerpos; y b) a la práctica de la sexualidad y de las actividades sexuales (Moreno y Pichardo, 2006). A partir de ahí se explica cómo el sistema sexo-género no solo sirve para explicar la subordinación de las mujeres en la dominación masculina, sino también la subordinación de unas prácticas sexuales sobre otras, en las que las prácticas no heterosexuales se consideran subalternas dentro un sistema heteronormado. Dicho sistema se ha traducido, por ejemplo, en la heterosexualidad obligatoria que se traduce en la penalización de las prácticas sexuales homosexuales.

La relación entre la dominación masculina y la heterosexualidad obligatoria es evidente para Adriene Rich (1980), que considera que la sociedad patriarcal ha determinado las prácticas sexuales de las mujeres, empujándolas a la heterosexualidad como única práctica sexual, garantizando así la propiedad masculina sobre el cuerpo y la sexualidad de las mujeres. De esta forma, la heterosexualidad obligatoria se constituye en una institución de la dominación masculina, como la maternidad patriarcal o la explotación 
económica, las cuales son establecidas por la legislación, los mandatos religiosos y los medios de comunicación.

Esta visión de la heterosexualidad obligatoria como régimen de dominación es compartido por Judith Butler (2007) al describir la matriz heterosexual como un régimen de poder-discurso que naturaliza los cuerpos, los géneros y los deseos dentro del binarismo hombre-masculino y mujerfemenino. Así, se presenta una abierta crítica al binarismo sexo-género y naturaleza-cultura, el cual pretende establecer una relación causal y limitada entre el sexo «naturalizado» y el género «culturalizado», desconociendo que tanto el sexo como el género pueden definirse más allá del binarismo hombremujer y masculino-femenino.

El concepto de identidad de género nace en la década de 1980 cuando gais, travestis, lesbianas y homosexuales lo utilizaron por primera vez para dar cuenta de múltiples identidades merecedoras de un estatus (Aguilar, 2008) que «traspasa la frontera de la sexualidad aceptada socialmente» (Fonseca y Quintero, 2009, p. 44). La identidad de género se refiere «al sentido personal de identidad individual como masculino o femenino, o como una combinación de estas» (Morrow y Messinger, 2006, p. 8. Traducción propia).

[184 ] La identidad de género puede corresponder o no con aquella que la sociedad le ha asignado a su identidad corporal. Esta identidad de género se puede exteriorizar de diferentes maneras: con intervenciones corporales médicas, apariencia, códigos de vestimenta, gestos, el modo de hablar, los modales entre otros. Esta externalización se conoce como expresión de género y «se relaciona con el cómo una persona exterioriza, manifiesta o expresa el género» (p. 8. Traducción propia).

Finalmente, la orientación sexual hace alusión a la profunda atracción emocional, afectiva o sexual por personas con una determinada identidad de género, diferente al suyo, el mismo o más de un género (Soler, 2005).

\section{Violencias contra las personas LGBTI en el conflicto armado interno colombiano}

La violencia contra las personas LGBTI puede adoptar principalmente tres formas: la ordinaria, la de prejuicio y la de crimen de lesa humanidad. En los delitos «ordinarios» los comportamientos lesionan derechos subjetivos individuales y no comprenden un propósito especial, ni se desarrollan en un contexto específico (Capella, 2005). En los «crímenes por prejuicio»la 
violencia se ejerce sobre personas LGBTI al ser percibidos como un grupo social inferior o categoría negativa que, por su identidad y expresión de género u orientación sexual, contradicen los roles hegemónicos asignados a sus cuerpos. En estos casos los autores utilizan extrema violencia y crueldad para castigar, subordinar, excluir y corregir (ACNUDH, Directiva General A/HRC/29/23 de 2015; Colombia Diversa, Caribe Afirmativo y Santamaría Fundación, 2016). En la actualidad, existen 72 países en los cuales es ilegal ser homosexual y también muchos donde se limita su libertad de expresión (Unidad de Víctimas, 2020, mayo 16).

En el conflicto armado las violencias contra miembros de la comunidad LGBTI, además de estar fundadas en un prejuicio acerca de la identidad y expresiones de género u orientación sexual, se realizan de manera sistemática y generalizada. Con este accionar, el grupo armado agresor busca aumentar su poder sobre un territorio. Estas violencias se presentan como una forma de «limpieza social» y hacen parte de un plan en el cual participa el Estado. Los autores obran con la convicción de que están legitimados para hacerlo porque defienden la normalidad heterosexual, a la vez que atacan la desviación. En un contexto donde las armas y la guerra representan la masculinidad, los cuerpos de las personas LGBTI se constituyen en territorios trasgresores de las lógicas heteronormativas y, por tanto, sufren de un tipo particular de victimización (IACHR, 2015; CNMH, 2015).

Una práctica frecuentemente empleada por los grupos paramilitares para ganar control sobre el territorio en el marco del conflicto armado colombiano fue la distribución de panfletos y la publicación de listados con nombres puntuales de personas a quienes se les exigía abandonar el territorio. Entre las víctimas de estas prácticas figuran miembros de las comunidades LGBTI y sus defensores (Margalit, 2018). Los panfletos eran dejados en las viviendas y comercios de los pueblos amenazando a sus víctimas con la muerte o declarándolos objetivos militares: «En ellos se manifestaban amenazas directas a ciertas poblaciones y sujetos socialmente indeseables: "putas", "sidosos", "maricas", "malparidos", "bazuqueros", "prepagos"» (Giraldo y Gallego, 2020, p. 82).

La promoción de la estigmatización de determinados grupos, como es el caso de las personas LGBTI, constituyó un instrumento político y disciplinante. Las personas LGBTI representaban lo impuro, sucio e indeseable y, por tanto, constituían una categoría inferior de individuos. El conflicto armado favoreció 
la construcción de un discurso heteronormativo donde se amplifican los prejuicios ya existentes contra las personas LGBTI y que sirve de justificación para las graves violaciones perpetradas contra ellas (Giraldo y Gallego, 2020).

En gran parte de la geografía colombiana los actores armados regularon no solo el aspecto social y económico, sino también la intimidad de sus habitantes, llegando incluso a intervenir en las relaciones de pareja. Al convertirse la homosexualidad en lo indeseable, en aquello que hay que extinguir, la integridad de todo individuo asociado a una persona LGBTI estaba en riesgo, lo que obligó a que las personas con orientación sexual diversa mantuvieran esta en secreto, relegada estrictamente al ámbito privado. La búsqueda de pareja afectiva se tornó entonces muy difícil, ya que reconocer o dar a entender la orientación sexual diversa ante otra persona dejaba a esta expuesta a un gran peligro (Giraldo y Gallego, 2020).

El conflicto armado apareja el resquebrajamiento del tejido social dejando aún más vulnerables a las personas LGBTI. El sentido de comunidad y solidaridad se pierde para ser reemplazados por la desconfianza generalizada, puesto que no se sabe quién es el informante, quién es el amigo y quién el enemigo. El autorreconocimiento como LGBTI no era necesario para ser [186] perseguido, bastaba con parecerlo o ser percibido como tal para ser víctima de ataques. En algunos pueblos los torneos de fútbol femenino fueron erradicados por considerar que eran caldo de cultivo para el lesbianismo (Giraldo y Gallego, 2020). Asimismo, se encuentran casos de «violación correctiva» como una forma particular de violencia contra lesbianas y mujeres trans (Margalit, 2018).

Si bien la forma particular de violencia de que son víctimas las personas LGBTI no es nueva, solamente empieza a tener visibilidad en la segunda mitad de la década de 1990, impulsada por el movimiento feminista y los instrumentos de derechos humanos surgidos para hacer frente a la exclusión, discriminación y violencias fundadas en el género. Es así como en Colombia surgen organizaciones defensoras de los derechos de esta población como Colombia Diversa (2004), Fundación Santamaría (2005) y Caribe Afirmativo (2009). Los informes desarrollados por dichas organizaciones fueron incluyendo de manera creciente la violencia diferenciada de que eran víctimas las personas LGBT en el marco del conflicto armado. Como resultado, el Estado colombiano empieza a incluir el enfoque de género en los programas de atención a las víctimas del conflicto y se introduce la orientación sexual 
en los formatos de registro de víctimas, así como la adopción de protocolos especiales de atención y la promoción de la denuncia (Giraldo, 2018).

Las vulneraciones de que son víctimas las personas LGBTI en el marco del conflicto armado colombiano no se limitan al bien jurídico de la vida y la libertad e integridad sexual, sino al derecho a vivir libre de violencia por prejuicio u odio basado en la orientación sexual. En un contexto donde las armas y la guerra representan la masculinidad, los cuerpos de las personas LGBTI se constituyen en territorios trasgresores de las lógicas heteronormativas y, por tanto, sufren de un tipo particular de victimización (IACHR, 2015; $\mathrm{CNMH}, 2015)$. Estas particularidades son las que sirven de fundamento a una movilización legal que exhorte al legislador a la tipificación diferenciada de estos crímenes.

\section{Fortalezas para la investigación y juzgamiento de las violencias contra personas LGBTI}

Los estudios críticos del derecho cuestionan la idea liberal del derecho como instrumento para superar la violencia (Brown y Williams, 2003; MacKinnon, 2014). Este debate resulta especialmente sensible en los estudios sobre derecho y movimientos sociales, en los cuales se han analizado las posibilidades que tiene el derecho para responder a las reivindicaciones de los grupos sociales tradicionalmente discriminados. En este sentido, ha sido relevante la idea de doble filo de Michael McCann (2006), según la cual el derecho tiene tanto la posibilidad de generar transformaciones sociales como de conservar el statu quo. Desde esa perspectiva, el derecho se ha convertido en un escenario de lucha para algunos movimientos sociales (Lemaitre, 2009). En esa misma vía Wendy Brown y Patricia Williams (2003) sostienen que, pese a la validez de las críticas a los derechos, para algunos movimientos sociales discriminados este discurso les permite actuar en la formalidad de la que han sido excluidos y gozar de un margen de protección.

El derecho penal se erige como mecanismo que tutela bienes jurídicos a través de la imposición de una pena que, mediante los fines de la prevención general, especial y la resocialización (Gimbernat, 1972; Roxin, 1981) pretende evitar futuros daños contra estos. Desde el surgimiento del derecho punitivo liberal el daño y el libre albedrío se erigieron como elementos imprescindibles de la responsabilidad (Carrara, 2000). Hoy en día se analizan en las categorías de la conducta punible, tipicidad, 
antijuridicidad y culpabilidad, y sirven de límite al derecho de castigar. El derecho penal moderno hunde sus raíces en la legalidad de los delitos y de las penas, la proporcionalidad de estas en relación con la gravedad de los hechos, la prescripción, la sujeción estricta del juez a la ley (Beccaria, 2015). Estos teoremas se fortalecieron con la herencia filosófica y política de la revolución francesa e influyeron en la reforma del derecho penal europeo. Esos presupuestos se afincaron en los Estados de derecho y se consolidaron en los países de tradición continental europea hasta bien entrado el siglo xx, de la mano de las teorías contractualistas que confiaron al legislador el resguardo de las garantías del reo.

El derecho penal se vio como un mecanismo de control social frente a conflictividades que lesionaban intereses jurídicos particulares: vida, integridad, libertad y patrimonio. No se había puesto de presente en la agenda legislativa, ni en la internacional, afectaciones de bienes jurídicos que sobrepasaran la mera individualidad y que conculcaran intereses de las naciones, como la paz, la seguridad, la tranquilidad o el hecho de existir, independientemente de la nacionalidad, raza, religión o pertenencia a un grupo humano determinado (Capella, 2005).

La legalidad del delito y de la pena, que había tomado fuerza en los Estados y encajaba en los planteamientos del positivismo jurídico, fue flexibilizada en los juicios de Núremberg (Comisión Colombiana de Juristas, 2012), al tipificar ex post y condenar a los militares alemanes por crímenes contra la paz y crímenes de guerra. El «crimen» se diferencia del «delito» en tanto aquel lesiona la paz y la seguridad internacional como asuntos que preocupan a todas las naciones, y lacera bienes jurídicos individuales (Capella, 2005).

La función simbólica del derecho penal de comunicar ciertas realidades (Abadía, 2018) quedó planteada con los juicios de Núremberg. Existen particulares motivaciones que llevan a un autor a realizar determinadas conductas en contra de un grupo humano y que los mismos móviles no estarían presentes respecto de otras personas. El Tribunal mostró a la luz pública que se asesinaba, lesionaba, torturaba y expropiaba a ciertas personas por el hecho de ser judíos, de lo que emergían patrones comunes de sistematicidad y generalidad (Werle, 2005). 
Estas circunstancias permiten nutrir la culpabilidad del autor, de la cual depende la tasación de la pena. Aquellas conductas que se realizan con un propósito específico, por ejemplo, asesinar a individuos por el hecho de pertenecer a un grupo humano y que hacen que la conducta se repita en el tiempo, deben ser castigados con mayor severidad que los delitos ordinarios. Finalmente, la naturaleza sistemática y generalizada de estos comportamientos hace que la afectación al bien jurídico trascienda del interés individual a la esfera colectiva, en cuya condena estarían interesadas todas las naciones porque se laceran bienes jurídicos internacionales (Capella, 2005).

El precedente que dejó Núremberg y la expedición de instrumentos internacionales de derechos humanos otorgan herramientas a las víctimas para el restablecimiento integral de sus derechos, comoquiera que reformulan el principio de legalidad, en el entendido de que nadie podría ser juzgado en materia penal si la conducta no estuviere prohibida previamente en el derecho aplicable, entendiendo por tal, no solo la ley del Estado, sino, además, cualquiera de las fuentes del derecho internacional (Comisión Colombiana de Juristas, 2012).

La reformulación del principio de legalidad permitió la creación de tribunales ad hoc, constituidos para el juzgamiento de «crímenes internacionales» — crímenes de lesa humanidad, crímenes de guerra y genocidio—, tales como el Tribunal Internacional para la ex-Yugoslavia (1993) y el Tribunal Penal Internacional para Rwanda (1994), por hechos que habían tenido lugar con anterioridad a su creación y habían lesionado bienes jurídicos colectivos que trastocaban los intereses de las naciones. Su tipificación fue realizada con posterioridad, en un proceso en el cual el Consejo de Seguridad de las Naciones Unidas tomó el precedente de Núremberg. Así, se consolidó la práctica de juzgar responsabilidades penales individuales en el foro internacional con estatutos punitivos creados con posterioridad a los hechos y por conductas que, al lacerar la paz y seguridad internacional, justificaban la categorización como conductas graves que habilitaban procesos penales en estas condiciones.

La constitución de poderes judiciales y estatutos punitivos ex post coadyuvaron a la creación de la Corte Penal Internacional, con la que se cerró la discusión sobre el principio de legalidad en el escenario internacional, pues el Estatuto de Roma fue la primera codificación convencional de estas 
conductas con la connotación de «crímenes internacionales». Con la creación de la Corte Penal Internacional surge una nueva aproximación a la justicia aplicable en los momentos de transición de la guerra a la paz o de la dictadura a la democracia. El derecho aplicable a los crímenes de lesa humanidad en el posconflicto deja de ser un derecho local contingente y excepcional, y pasa a ser un derecho universal estatuido, basado en el principio de legalidad y parte integral del derecho doméstico de los Estados parte del Estatuto de Roma (Ibarra, 2016).El segundo fenómeno se refiere a la adopción en los ordenamientos jurídicos internos de lo que fuera una costumbre internacional. Los países que ya tenían bien consolidado el principio de legalidad bajo la fórmula clásica del nullum crimen, nulla poena sine lege, que solo admitía el juzgamiento por una ley en sentido estricto que tipificara la prohibición y la respectiva sanción, empezaron a condenar a los autores responsables de estas conductas con fundamento directo en las fuentes del derecho internacional, principalmente en la costumbre. La aplicación del Estatuto de Roma presentaba dificultades en aquellos países que no lo habían suscrito o que, de haberlo hecho, conduciría a la utilización retroactiva de una ley más gravosa frente a hechos ocurridos con anterioridad a su promulgación, si se tiene en cuenta que muchas de las naciones no habrían consagrado los crímenes de lesa humanidad dentro de sus códigos penales con la entidad de tal, siendo de amplia tipificación únicamente los delitos ordinarios.

Por citar un ejemplo, Adolfo Scilingo, teniente de fragata de la Armada de la República Argentina y miembro de Escuela Mecánica (ESMA), participó entre 1976 y 1983 en varios asesinatos, desapariciones forzadas, detenciones ilegales y torturas durante el periodo dictatorial argentino (Comisión Colombiana de Juristas, 2012). Por estos hechos Scilingo, fue condenado el 19 de abril de 2005 a 640 años de privación de la libertad por crímenes de lesa humanidad. Este tipo penal (art. 607 bis) se incorporó al Código Penal español en 2004, es decir, con posterioridad a la fecha en la cual ocurrieron los hechos, lo que constituía una aplicación retroactiva de la ley penal con carácter desfavorable. No obstante, la Audiencia Nacional Española justificó la validez de dicha norma al afirmar que representaba la positivización de normas internacionales preexistentes integrantes, por sus características y objeto, del ius cogens. Por ello, estas normas tendrían validez obligatoria erga omnes (Hormazabal, 2005).

Estas aperturas que han generado los escenarios jurídicos locales han estado respaldadas por la adopción de cláusulas constitucionales que 
incorporan y armonizan las fuentes del derecho internacional en los textos constitucionales bajo figuras como las del bloque de constitucionalidad (Uprimny, 2009) y el control de convencionalidad (Hitters y Fappiano, 2007). Con estas figuras se reconocen efectos jurídicos vinculantes a los tratados internacionales de derechos humanos y a las interpretaciones autorizadas, a efectos de materializar las obligaciones de los Estados de respetar, proteger y garantizar los derechos humanos en sus territorios (Martínez, 2019).

En Colombia, aun cuando se ha avanzado en la consagración de crímenes graves como la desaparición forzada, el genocidio y los delitos contra el derecho internacional humanitario, actualmente no se han tipificado los crímenes de lesa humanidad. Sin embargo, la posibilidad de investigar, juzgar y sancionar conductas punibles como crímenes de lesa humanidad, con fundamento directo en las fuentes del derecho internacional, en aquellos ordenamientos jurídicos en los que, como el colombiano, no existe tal tipificación, tiene asidero en las siguientes consideraciones:

a) El derecho penal internacional ha consolidado la práctica de investigar, juzgar y condenar a los individuos tomando como referente de legalidad las fuentes del derecho internacional, sean consuetudinarias o convencionales (Werle, 2005).

b) Los tribunales nacionales han reformulado el aforismo nullum crimen, nulla poena sine lege, por el de nullum crimen sine iure. Colombia no ha sido ajena a estas vicisitudes. Se han adelantado juicios e impuesto condenas por conductas constitutivas de crímenes de lesa humanidad, aunque se tratara de hechos que, a la luz del derecho nacional, configuran delitos ordinarios, sobre los cuales ha operado el fenómeno de la prescripción (Comisión Colombiana de Juristas, 2012). Como ejemplos se pueden citar las sentencias de responsabilidad de César Pérez García por la masacre de Segovia (Corte Suprema de Justicia, Radicado 33118 de 2013) y de Miguel Alfredo Maza Márquez por el asesinato de Luis Carlos Galán (Corte Suprema de Justicia, Radicado 44312 de 2016). El común denominador de estas providencias es el análisis de los patrones de sistematicidad y generalidad en los cuales tuvieron ocurrencia los hechos como elementos esenciales de los crímenes de lesa humanidad que permitieron nutrir de contenido las disposiciones del Decreto 100 de 1980, estatuto punitivo aplicable para la época de los hechos, haciendo improcedente la figura de la prescripción. 
c) La persecución de los crímenes de lesa humanidad se fundamentó en las aperturas constitucionales de 1991 en relación con la incorporación de tratados internacionales sobre derechos humanos que, según los artículos 93, 94 y 214 , prevalecen en el orden interno y que en el precedente constitucional se han interpretado como parte integrante del texto constitucional con la misma jerarquía y fuerza normativa (Martínez, 2019). El bloque de constitucionalidad ha servido para sustentar las condenas con fundamento en normas del derecho internacional, principalmente en la costumbre internacional que, para la época en la que tuvieron lugar los hechos motivo de juzgamiento, ya se había consolidado en el escenario internacional. El tribunal nacional se ha apoyado en el principio de legalidad contenido en la Declaración Universal de los Derechos Humanos (art. 11), en el Pacto Internacional de Derechos Civiles y Políticos (art. 15.1), y en la Convención Americana de Derechos Humanos (art. 9) que contemplan la facultad de emitir sentencias de responsabilidad penal con fundamento en el derecho aplicable, sea nacional o internacional (Martínez, 2019).

La norma fundamento de la punición ha sido el Código Penal vigente para la época de los sucesos, esto es, el Decreto 100 de 1980; sin embargo, comoquiera que esta normatividad consagró únicamente los delitos ordinarios, las conductas para la fecha de juzgamiento, en principio, ya se encontraban prescritas. No obstante, se trataba de una norma nacional que contemplaba núcleos de conducta reprochables, en la que estaba perfectamente delimitada la prohibición y la pena, y de esta manera se garantizaba la previsibilidad y accesibilidad como los presupuestos esenciales del principio de legalidad, por lo que la única dificultad giraba en torno al instituto de la prescripción (Ramelli, 2012). Para garantizar la procedencia de la acción penal se acudió a dos argumentos centrales: la vigencia de la Convención sobre la imprescriptibilidad de los crímenes de guerra y de los crímenes de lesa humanidad (1968), la cual permite adelantar la persecución punitiva de estas conductas en todo tiempo, aun en aquellos eventos en que dichos actos no constituyeran «una violación del derecho interno del país donde fueron cometidos» (art. 1, literal b).

d) Esta práctica de investigar, juzgar y condenar por crímenes de lesa humanidad, aun cuando no estuvieran tipificados en el ordenamiento jurídico interno, tiene como argumento central la reivindicación y restablecimiento integral de los derechos de las víctimas, quienes han adquirido protagonismo en el proceso penal interno. La jurisprudencia constitucional ha establecido 
que los sujetos pasivos de comportamientos que constituyen crímenes de lesa humanidad tienen derechos a la verdad, justicia y reparación y que, en este escenario, el proceso penal constituye un medio idóneo para garantizarlos (Corte Constitucional, Sentencia C-031 de 2018).

e) Lo anterior pone en el foro legislativo y judicial la existencia de conductas que traspasan la esfera de la afectación individual de derechos subjetivos y dan al traste con daños que, al ser sistemáticos y generalizados, configuran graves afrentas a la paz y a la seguridad (Capella, 2005); asimismo, brinda elementos para analizar la culpabilidad del autor, en relación con los móviles de estas infracciones a la ley penal, como cuando la pertenencia a un grupo étnico, político o religioso, o en aquellas circunstancias en las que se causa la muerte de una mujer por el hecho de ser mujer, o se atenta contra la vida, la integridad o la libertad sexual de individuos por su identidad y expresiones de género, o por su orientación sexual en el marco de un plan o política de Estado. La generalidad y sistematicidad de conductas que atentan contra bienes subjetivos individuales adquiere una gravedad inusitada que amerita la intervención punitiva, dada la connotación del daño a intereses jurídicos colectivos, y habilita el levantamiento de la prescripción cuando además se han cometido las conductas como parte de un plan o política de Estado, en las cuales han incurrido funcionarios del Estado o terceros que han actuado con la colaboración, aquiescencia o tolerancia de aquellos, por acción u omisión.

En este escenario, el operador jurídico cuenta con elementos de contexto imprescindibles para analizar la mens rea del autor y pone en evidencia la existencia de propósitos específicos que lo llevan a cometer una serie de violaciones a los derechos humanos que no estarían presentes frente a otro grupo poblacional (Agatón, 2017). Por ejemplo, el feminicidio en Puebla, México, perpetrado por particulares y frente a los cuales el Estado no adelantó ninguna diligencia de reproche o restablecimiento de derechos de las víctimas (Caso González y Otras Vs. México, 2009), comoquiera que cumple con los presupuestos de sistematicidad y generalidad, configura crímenes de lesa humanidad y cuya condena demuestra que los agentes incurrieron en esta tipología de conductas frente a mujeres por el hecho de ser mujeres (Agatón, 2013).

Lo mismo sucede con las violaciones a los derechos humanos de miembros de la comunidad LGBTI en el conflicto armado interno, en las cuales 
los perpetradores ostentan un dolus especialis que los lleva a cometer estos comportamientos debido a su identidad de género, expresiones de género u orientación sexual como una herramienta para corregir, limpiar, castigar y para dominar, y que no estarían presentes en los asesinatos o lesiones de poblaciones heterosexuales.

\section{Debilidades para la investigación y juzgamiento de las violencias contra personas LGBTI}

En el ordenamiento jurídico interno existen diversas circunstancias por las cuales no se ha ejercido la persecución penal de las variadas violaciones a los derechos humanos de comunidades LGBTI como crímenes de lesa humanidad. El primero de ellos es el principio de legalidad. En el apartado anterior se abordó la flexibilización de esta garantía procesal hacia el entendimiento del nullum crimen sine iure, mediante el cual el Estado puede adelantar un juicio de responsabilidad penal por crímenes de lesa humanidad, aun cuando tal categoría no estuviera consagrada en el derecho interno. Sin embargo, el artículo 29 de la Constitución Política de Colombia de 1991 contiene una definición de legalidad que se acompasa con el aforismo del derecho penal liberal del nullum crimen, nulla poena sine lege, bajo el cual

[194] nadie puede ser juzgado sino conforme a las leyes preexistentes, entendiendo por tales aquellas previsiones normativas emanadas exclusivamente por el legislador.

La cultura jurídica predominante ha estado centrada en que solo la ley doméstica puede consagrar la conducta prohibida y la pena. Esta situación puede obedecer a la consolidación del Estado de Derecho en Colombia que parte de la Carta Constitucional de 1886 y está aún presente en el poder judicial en las postrimerías del siglo xx, el cual se niega a reconocer el efecto vinculante de instrumentos internacionales en el escenario punitivo, bajo una suerte de dualismo jurídico que pretende otorgar eficacia de las normas supranacionales, únicamente para los conflictos entre los Estados, no así para aquellas que emergen en las relaciones entre estos y los individuos de un país (Martínez, 2019).

El argumento de la soberanía, de la división tripartita de poderes, del principio de favorabilidad y de la seguridad jurídica siguen siendo talanqueras para adelantar juicios con fundamento en el derecho internacional. Los casos que se han adelantado, en este sentido, han sido escasos y se han dispuesto 
para lo que socialmente se ha considerado «afrenta grave para los derechos humanos», en cuya categoría no se han abordado las violaciones a los derechos de comunidades LGBTI. El segundo argumento en torno al cual gravita la falta de procesamiento de las violaciones a los derechos subjetivos de comunidades LGBTI como crímenes de lesa humanidad tiene relación directa con los efectos de los tratados internacionales que propenden por la protección de tales garantías y de los cuales puede desprenderse un fundamento directo para su punición.

Es necesario distinguir los instrumentos del derecho penal internacional de aquellos que se ubican en el área del derecho internacional de los derechos humanos (Werle, 2005). Dentro de los primeros, ninguno, salvo la Convención sobre la imprescriptibilidad de los crímenes de guerra y de los crímenes de lesa humanidad (1968) y el Estatuto de Roma de la Corte Penal Internacional (2002) establecen los elementos objetivos del tipo penal que se viene analizando. Para la identificación de la tipicidad objetiva, la Convención sobre la imprescriptibilidad remite a la definición del Estatuto del Tribunal Militar Internacional de Núremberg (1945) y a las resoluciones de la Asamblea General de las Naciones Unidas 3 (I) y 95 (I) de 1946; sin embargo, se ha argüido que la Convención no ha sido ratificada por el Estado colombiano (Posada, 2010) y, por ello, no puede otorgársele efectos en el sistema normativo local (Ambos, 2004). De otro lado, sobre la aplicación del Estatuto de Roma (2002) como fundamento directo de la punibilidad de crímenes de lesa humanidad en el proceso penal interno se han elevado diversas posturas que dificultan la imposición de la condena en el ámbito en el que se viene estudiando, relacionadas con la fecha de entrada en vigor para los Estados y los ámbitos de aplicación que estos han dispuesto (Posada, 2010).

El Estatuto de Roma fue aprobado en Colombia mediante la Ley 742 de 5 de junio de 2002 y declarada exequible por la Corte Constitucional en Sentencia C-578 de 2002, en la cual, aclaró que la eficacia del instrumento convencional estaría supeditada dentro del propio ámbito del Estatuto, esto es, para investigaciones, juzgamientos y sanciones de responsabilidades penales individuales en el escenario internacional bajo el principio de complementariedad. Si bien este instrumento fue ratificado en 2002, el Gobierno colombiano estableció una reserva por el término de siete años para la competencia de la Corte frente crímenes de guerra. Esto quiere decir que 
la Corte Penal Internacional no tendría competencia frente aquellos hechos que tuvieron ocurrencia con anterioridad al 2009. Es justamente en ese interregno en el cual el conflicto armado en Colombia estuvo exacerbado y se cometieron graves violaciones a los derechos humanos de personas LGBTI.

Frente a los tratados internacionales sobre derechos humanos que prohíben atentados contra los derechos subjetivos individuales como la vida, la integridad, la libertad personal, la libertad sexual y el derecho a existir libre de violencia, tienen una naturaleza que les impide ser ejecutables por sí mismos —non-self executing—, lo que significa que requieren de su transformación en derecho interno, ya que el derecho internacional no especifica por sí mismo cómo debería ser aplicado y fortalecido en el ámbito nacional (Ferdinandusse, 2006). En este sentido, el derecho internacional da a los Estados la libertad de implementar y cumplir sus obligaciones internacionales en cualquier modo que ellos encuentren conveniente (Brotons, 2007; Herdegen, 2005). Bajo este entendimiento, es posible avizorar en la norma convencional el establecimiento de la prohibición — no matar, no ejercer actos de violencia sexual, no discriminar, entre otros-, bajo la categoría de un mandato dirigido a los Estados contenido en obligaciones de respeto, protección y garantía de los derechos humanos. Empero, ninguno de ellos trae aparejada la sanción que de manera individual se le impondría a quien los contrariara.

Comoquiera que las cláusulas de un tratado no tienen los componentes de una norma jurídica, a la manera como lo había delimitado el positivismo jurídico — descripción de la conducta prohibida y de la sanción- (Kelsen, 1982), se pone en entredicho la seguridad jurídica del destinatario de la norma, en cuanto a la previsibilidad y accesibilidad del comportamiento y de la pena. La dificultad se viene a reforzar frente a aquellos Estados que, como el colombiano, han estado imbuidos por una tradición legocentrista (López, 2008), bajo una filosofía de estricta reserva legal de los delitos y de las penas. La estricta legalidad nacional es insuficiente para condenar estas conductas como lo que son, crímenes de lesa humanidad, no solo porque no existe tal tipificación en la ley penal colombiana, sino porque la normatividad existente encuadra las violaciones a los derechos de la comunidad LGBTI como delitos ordinarios, sobre las cuales, en el mejor de los casos, puede llegar a operar la causal de agravación punitiva contenida en el numeral 3 del artículo 58 de la Ley 599 de 2000, en aquellos eventos en los cuales la conducta esté inspirada en motivaciones de intolerancia y discriminación basadas en el 
sexo, la orientación o la identidad de género, según lo ha decantado la Corte Constitucional (Sentencia C-257 de 2016).

Colombia Diversa ha denunciado que el agravante mencionado no se aplica pese a la existencia de evidencias que permiten inferir el dolo especial en el autor, permeado por móviles discriminatorios y de intolerancia. En su lugar, las investigaciones parten de la hipótesis de la configuración de un crimen pasional y bajo estas presunciones se diseña el programa metodológico y se estructura la teoría del caso, lo que conduce a la reducción de la punibilidad a la luz del artículo 57 del Código Penal y a la invisibilización de la existencia de crímenes por prejuicio, en los cuales está presente un móvil discriminatorio (Colombia Diversa, 2012; Colombia Diversa, Caribe Afirmativo y Santamaría Fundación, 2016). El derecho penal termina comunicando que la identidad y expresiones de género o la orientación sexual constituyen un comportamiento grave e injusto del cual emerge el estado emocional de ira e intenso dolor.

Las violaciones a los derechos subjetivos de personas pertenecientes a comunidades LGBTI no han sido abordadas como graves debido a dos factores esenciales: el primero, relacionado con la exclusión histórica, jurídica y social de sus derechos que culmina desmontando su calidad de sujetos de especial protección constitucional; y el segundo, relativo a la ausencia de registros de denuncias por miedo a ser víctimas de humillación, discriminación y poca atención de las autoridades estatales, que al brindar algún tratamiento en el proceso penal no asumen estas realidades con perspectiva de género, y el periplo que, por demás, es revictimizante, termina en una completa denegación de justicia e impunidad (IACHR, 2015). En ningún caso, por ejemplo, se ha aplicado la causal de agravación del artículo 58.3 del Código Penal, a pesar de que, en muchos casos, existen medios de convicción que permiten establecer el «prejuicio», «la discriminación» o la «intolerancia» como móvil determinante de la conducta (Colombia Diversa, Caribe Afirmativo y Santamaría Fundación, 2016).

\section{Conclusiones}

Los grupos armados estatales e ilegales han cometido violencias contra personas LGBTI en ocasión del conflicto armado colombiano para demostrar dominio e imponer lógicas de heterosexualidad como obligatorias: la guerra es la representación de la masculinidad, se ejerce sobre un territorio y los cuerpos de lesbianas, gais, trans, bisexuales e intersexuales se ven como transgresoras 
de las normas sociales impuestas. Estos menoscabos de derechos subjetivos individuales constituyen violencias de género porque reproducen el binario sexo-género que pretende asignar una determinada identidad de género a un sexo y se utiliza para limpiar, corregir, rechazar, excluir y estigmatizar por la identidad y expresión de género, o por la orientación sexual.

En el ámbito penal estas violencias se han invisibilizado, el derecho penal no las ha nombrado, no se investigan los elementos de contexto, ni el móvil con el cual han obrado paramilitares, guerrilleros y fuerza pública, lo que repercute en la reconstrucción de la memoria histórica como garantía de no repetición. El derecho penal debe estar en capacidad de nombrar realidades, su función simbólica va más allá de la prevención general y especial como fines de la pena. Debe estar en capacidad de representar la existencia de motivos que llevan a ejercer todo tipo de violencias contra miembros de poblaciones LGBTI que no están presentes en las conductas delictivas cometidas en contra de heterosexuales. En aquellas existe una base discriminatoria que implica que sus derechos son violentados por lo que son, por cómo se expresan y cómo se reconocen socialmente. La historia de estos comportamientos es la misma del conflicto armado, es igual a la de la guerra que se erigió como escenario de masculinidades violentas, de rechazo, corrección y dominación de lo diferente, lo que demuestra su naturaleza generalizada y sistemática.

El sistema legal y judicial colombiano tiene muchos retos, entre ellos, superar el discurso de la estricta legalidad para generar aperturas hacia la judicialización de estos comportamientos como crímenes de lesa humanidad con fundamento directo en las fuentes del derecho internacional; y actuar con debida diligencia en torno a esta tipificación en el diseño del programa metodológico y en el juicio, así como orientar la actividad investigativa y judicial con enfoque de género para que no reproduzca las estructuras de dominación y exclusión presentes en las prácticas sociales.

\section{Referencias bibliográficas}

1. Abadía, Gloria. (2018). Feminismos y sistema penal. Retos contemporáneos para una legitimación del sistema penal. Bogotá, D. C.: Universidad de los Andes.

2. Agatón, Isabel. (2013). Justicia de Género. Un asunto necesario. Bogotá, D. C.: Temis.

3. Agatón, Isabel. (2017). Si Adelita se fuera con otro. Bogotá, D. C.: Temis.

4. Aguilar, Teresa. (2008). El sistema sexo-género en los movimientos feministas. Amnis, 8. https://doi.org/10.4000/amnis.537 
Violaciones graves a derechos humanos de comunidades LGBTI en el conflicto armado...

5. Ambos, Kai. (2004). Problemas seleccionados en torno a los crímenes más graves (core crimes) en el derecho penal internacional. https://www.mpf.gov.ar/docs/ RepositorioB/Ebooks/qdpi080.pdf

6. Asamblea General Naciones Unidas. Alto Comisionado de las Naciones Unidas para los Derechos Humanos. Directiva General A/HRC/29/23. (4 de mayo de 2015). Discriminación y violencia contra las personas por motivos de orientación sexual e identidad de género. Recuperado de https://www.un.org/en/ga/search/view_doc. asp? symbol = A/HRC/29/23\&referer $=/$ english/\&Lang $=\mathrm{S}$

7. Beccaria, Cesare. (2015). De los delitos y de las penas. Madrid: Universidad Carlos III.

8. Brotons, Antonio. (2007). Derecho internacional. Valencia: Tirant Lo Blanch.

9. Brown, Wendy y Williams Patricia. (2003). La crítica de los derechos. Bogotá, D. C.: Siglo del Hombre.

10. Burin, Mabel. (1996). Género y psicoanálisis: subjetividades femeninas vulnerables. En: Dio Bleichmar, Emilce y Burín, Mabel (comps.). Género, psicoanálisis, subjetividad (pp. 61-99). Buenos Aires: Paidós.

11. Butler, Judith. (2007). El género en disputa. El feminismo y la subversión. Buenos Aires: Paidós.

12. Capella, Margalida. (2005). La tipificación internacional de los crímenes contra la humanidad. Valencia: Tirant Lo Blanch.

13. Carrara, Francesco. (2000). Programa del Curso de Derecho Criminal. San José de Costa Rica: Jurídica Continental.

14. Centro Nacional de Memoria Histórica (CNMH). (2015). Aniquilar la diferencia. Lesbianas, gays, bisexuales y transgeneristas en el marco del conflicto armado colombiano. Bogotá, D. C.: CNMH.

15. Colombia. Asamblea Nacional Constituyente. Constitución Política de la República de Colombia. (20 de julio de 1991). http://www.secretariasenado.gov.co/ senado/basedoc/constitucion_politica_1991.html

16. Colombia. Presidencia de la República. Decreto 100. (23 de enero de 1980). Por el cual se expide el nuevo Código Penal. http://www.suin-juriscol.gov.co/ viewDocument.asp? $\mathrm{id}=1705120$

17. Colombia. Corte Constitucional. Sentencia C-578. (30 de julio de 2002). https://www.corteconstitucional.gov.co/relatoria/2002/C-578-02.htm

18. Colombia. Corte Constitucional. Sentencia C-257. (18 de mayo de 2016). https://www.corteconstitucional.gov.co/relatoria/2016/C-257-16.htm

19. Colombia. Corte Constitucional. Sentencia C-031. (2 de mayo de 2018). https://www.corteconstitucional.gov.co/relatoria/2018/C-031-18.htm

20. Colombia. Corte Suprema de Justicia. Radicado 33118. (15 de mayo de 2013). https://cortesuprema.gov.co/corte/wp-content/uploads/relatorias/pe/b2may2013/ Boletin\%20Informativo\%202013-05-21.pdf 
21. Colombia. Corte Suprema de Justicia. Radicado 44312. (23 de noviembre de 2016). https://cortesuprema.gov.co/corte/wp-content/uploads/relatorias/pe/ b1dic2016/SP16905-2016(44312).doc

22. Colombia Diversa. (2012). Homicidios, Abuso policial, e impunidad. Informe de Derechos Humanos de personas LGTB en Colombia, 2010-2011. Bogotá, D. C.: Visión Gráfica.

23. Colombia Diversa, Caribe Afirmativo y Santamaría Fundación. (2016). Cuerpos excluidos, rostros de impunidad. Informe de violencia hacia personas LGBT en Colombia, 2015. Bogotá, D. C.: Colombia Diversa. https://colombiadiversa.org/ ddhh-Igbt/Informe-Violencia-LGBT-Colombia-DDHH-2015.pdf

24. Comisión Colombiana de Juristas. (2012). Retroactividad penal de crímenes internacionales. Bogotá, D. C.: Opciones Gráficas.

25. Corte Interamericana de Derechos Humanos. Caso González y Otras Vs. México (19 de noviembre de 2009). https://www.corteidh.or.cr/cf/Jurisprudencia2/ ficha_tecnica.cfm?nld_Ficha $=347$ \&lang $=\mathrm{e}$

26. Cranny-Francis, Anne; Waring, Wendy; Stavropoulos, Pam y Kirkby, Joan. (2003). Gender Studies: Terms and Debates. New York: Palgrave Macmillan. https:// doi.org/10.1007/978-0-230-62916-5

27. Ferdinandusse, Ward. (2006). Direct Application of International Criminal Law in National Courts. Cambridge: Cambridge University. https://doi.org/10.1007/97890-6704-707-4

[200 ] 28. Firestone, Shulamith. (1976). La dialéctica del sexo. Barcelona: Kairós.

29. Fonseca, Carlos y Quintero, María. (2009). La Teoría Queer: la de-construcción de las sexualidades periféricas. Sociológica, 24 (69), pp. 43-60.

30. Gimbernat, Enrique. (1972). ¿Tiene futuro la dogmática jurídico penal? Madrid: Civitas.

31. Giraldo, Sebastián. (2018). Diversidad sexual y de género en el marco del conflicto armado en Colombia. Algunas reflexiones para su estudio. Revista Eleuthera, 19, pp. 115-133. doi: 10.17151/eleu.2018.19.7

32. Giraldo, Sebastián y Gallego, Gabriel. (2020). Regulación y victimización del homoerotismo entre hombres en contextos de conflicto armado en Colombia. Debate Feminista, 30 (60), pp. 75-99. doi: 10.22201/cieg.2594066xe.2020.60.04

33. Haraway, Donna. (1995). Ciencia, cyborgs y mujeres. La reinvención de la naturaleza. Madrid: Cátedra.

34. Herdegen, Matthias. (2005). Derecho internacional público. México, D. F.: Instituto de Investigaciones Jurídicas, Fundación Konrad Adenauer.

35. Hitters, Juan y Fappiano, Óscar. (2007). Derecho internacional de los derechos humanos. Buenos Aires: Ediar.

36. Hormazabal, Hernán. (2005). Crímenes internacionales, jurisdicción y principio de legalidad penal. En: Pérez Cepeda, Ana Isabel (dir.). El principio de Justicia Universal, fundamentos y límites (pp. 237-268). Valencia: Tirant Lo Blanch. 
Violaciones graves a derechos humanos de comunidades LGBTI en el conflicto armado...

37. Ibarra, Adelaida. (2016). Justicia transicional: la relación derecho-poder en los momentos de transición. Revista de Derecho, 45, pp. 237-261. https://doi. org/10.14482/dere.45.7978

38. Inter-American Commission on Human Rights (IACHR). (2015). Violence against LGBT Persons in the Americas. http://www.oas.org/en/iachr/reports/pdfs/ ViolenceLGBTIPersons.pdf

39. Jaramillo, Isabel (2000). La crítica feminista al derecho. En: West, Robin. Género y teoría del derecho (pp. 26-66). Bogotá, D. C.: Uniandes.

40. Kelsen, Hans (1982). Teoría pura del derecho. México, D. F.: Universidad Autónoma de México.

41. Lamas, Marta. (2013). El género. La construcción cultural de la diferencia sexual. México, D. F.: Librero.

42. Lemaitre Ripoll, Julieta. (2009). El derecho como conjuro. Bogotá, D. C.: Uniandes.

43. López, Diego. (2008). La armonización del derecho internacional de los derechos humanos en el derecho penal colombiano. Revista Colombiana de Derecho Internacional, 6 (12), pp. 317-351.

44. MacKinnon, Catherin. (2014). Feminismo inmodificado. Discursos sobre la vida y el Derecho. Buenos Aires: Siglo xxı.

45. Margalit, Alon (2018). Still a Blind Spot: The Protection of LGBT Persons During Armed Conflict and Other Situations of Violence. International Review of the Red Cross, 100 (1-2-3), pp. 237-265. doi:10.1017/S1816383119000201

46. Martínez, Gloria. (2019). Aplicación del derecho internacional por los jueces y tribunales nacionales. Bogotá, D. C.: Escuela Judicial Rodrigo Lara Bonilla.

47. Moreno, Ángel y Pichardo, José. (2006). Homonormatividad y existencia sexual. Amistades peligrosas entre género y sexualidad. AIBR Revista de Antropología Iberoamericana, 1 (1), pp. 143-156. https://doi.org/10.11156/aibr.010110

48. McCann, Michael. (2006). Law and Social Movements: Contemporary Perspectives. Annual Review of Law and Social Science, 2, pp. 17-38. https://doi. org/10.1146/annurev.lawsocsci.2.081805.105917

49. Millet, Kate. (1995). Política sexual. Madrid: Cátedra.

50. Morrow, Deana \& Messinger, Lori (Eds.). (2006). Sexual Orientation and Gender Expression in Social Work Practice: Working with Gay, Lesbian, Bisexual, and Transgender People. Nueva York: Columbia University.

51. Posada, Ricardo. (2010). Los delitos de lesa humanidad. Cuadernos de Derecho Penal, 4, pp. 129-156.

52. Ramelli, Alejandro. (2012). Reflexiones sobre el principio de legalidad en investigaciones por crímenes de lesa humanidad en Colombia. En: Velásquez, Fernando y Vargas, Renato (comps.). Presente y futuro de la Justicia Penal Internacional. Bogotá, D. C.: Universidad Sergio Arboleda. 
53. Rich, Adrienne. (1980). Compulsory Heterosexuality and Lesbian Existence. Women: Sex and Sexuality, 5 (4), pp. 631-660. https://doi.org/10.1086/493756

54. Roxin, Claus. (1981). Culpabilidad y prevención en el derecho penal. Madrid: Reus.

55. Rubin, Gayle. (1986). El tráfico de mujeres: notas sobre la «economía política» del sexo. Nueva Antropología, 8 (30), pp. 95-145.

56. Sánchez, Robinson. (2013). Hablando de derechos con las trans de la zona de alto impacto. Una descripción del rol que juega el discurso de los derechos en las agendas sociales de las organizaciones de mujeres transgeneristas en ejercicio de la prostitución en la Localidad de Los Mártires de Bogotá (Tesis inédita de maestría). Universidad de los Andes, Bogotá, D. C.

57. Scott, Joan. (1986). El género: una categoría útil para el análisis histórico. En: Lamas, Marta (comp.). El género. la construcción cultural de la diferencia sexual (pp. 265-302). México, D. F.: PUEG.

58. Soler, Franklin. (2005). Evolución y orientación sexual. Diversitas, 1 (2), pp.161-173. https://doi.org/10.15332/s1794-9998.2005.0002.04

59. Unidad para la Atención y Reparación Integral a las Víctimas (2020, mayo 16). La Unidad reafirma su compromiso con las víctimas del conflicto armado con orientaciones sexuales e identidades de género diversas. Recuperado de https://www. unidadvictimas.gov.co/es/enfoques-diferenciales/la-unidad-reafirma-su-compromisocon-las-victimas-del-conflicto-armado-con

[202] 60. Uprimny, Rodrigo (2009). Bloque de constitucionalidad, derechos humanos y proceso penal. Bogotá, D. C.: Escuela Judicial Rodrigo Lara Bonilla.

61. Werle, Gerhard. (2005). Tratado de Derecho Penal Internacional. Valencia: Tirant Lo Blanch. 